\title{
Optimization of Transpiration and Potential Growth Rates of 'Kardinal' Rose with Respect to Root-zone Physical Properties
}

\author{
Michael Raviv \\ Ministry of Agriculture, Agricultural Research Organization, Newe Ya'ar Research Center, Department \\ of Ornamental Horticulture, P.O. Box 1021, Ramat Yishay, 30095, Israel
}

J. Heinrich Lieth and David W. Burger

Department of Environmental Horticulture, University of California, Davis, CA 95616-8587

Rony Wallach

The Seagram Center for Soil and Water Sciences, Faculty of Agriculture, The Hebrew University of Jerusalem, P.O. Box 12, Rehovot 76100, Israel

\begin{abstract}
ADDITIONAL INDEX wORDs. hydraulic conductivity, metabolic heat rate, microcalorimetry, potential growth, respiration rate, Rosa $\times$ hybrida, transpiration

Abstract. Physical characteristics of two media were studied concerning water availability to roots, as reflected in specific transpiration rate, stomatal conductance, and specific growth rate of very young leaflets of 'Kardinal' rose (Rosa Xhybrida L.), grafted on Rosa canina L. 'Natal Brier'. Plants were grown in UC mix [ $42 \%$ composted fir bark, 33\% peat, and $25 \%$ sand (by volume)] or in coconut coir. Water release curves of the media were developed and hydraulic conductivities were calculated. Irrigation pulses were actuated according to predetermined media moisture tensions. Transpiration rate of plants was measured gravimetrically using load cells. Specific transpiration rate (STR) was calculated from these data and leaf area. STR and stomatal conductance were also determined using a steady-state porometer. Specific growth rate $\left(\mathbf{R}_{\mathrm{SG}}\right)$ of young leaflets was calculated from the difference between metabolic heat rate and respiration rate, which served as an indicator for growth potential. Low STR values found at tensions between 0 and $1.5 \mathrm{kPa}$ in $\mathrm{UC}$ mix suggest this medium has insufficient free air space for proper root activity within this range. Above $2.3 \mathrm{kPa}$, unsaturated hydraulic conductivity of UC mix was lower than that of coir, possibly lowering STR values of UC mix-grown plants. As a result of these two factors, STR of plants grown in coir was $20 \%$ to $30 \%$ higher than that of plants grown in UC mix. STR of coir-grown plants started to decline only at tensions around $4.5 \mathrm{kPa}$. Yield (number of flowers produced) by coir-grown plants was $19 \%$ higher than UC mix-grown plants. This study demonstrated the crucial role of reaching sufficient air-filled porosity in the medium shortly after irrigation. It also suggests that hydraulic conductivity is a more representative measure of water availability than tension.
\end{abstract}

Transpiration $(\mathrm{T})$ is an essential process in plant life. Optimization of dry matter production can be realized when actual $\mathrm{T}$ is close to potential $\mathrm{T}$ due to the dual role of stomata in controlling leaf temperature through water vapor exit and $\mathrm{CO}_{2}$ entry.

The role of transpirational cooling in maintaining an optimal tissue temperature range is more critical in greenhouse-grown crops than in field-grown crops. Daytime air temperature within a greenhouse is generally higher than ambient. Moreover, radiative and convective heat losses from plant surfaces are smaller due to the presence of the greenhouse cover. Thus, the well being of a greenhouse-grown plant is more dependent on uninterrupted transpiration than its field-grown counterpart. Since water storage capacity of a rose plant (Rosa $\times$ hybrida) is relatively small, a balance must be maintained between water flux into and out of the plant, so as to prevent water stress.

Water flux from the root zone through the plant, to the air is determined by hydraulic conductance (C) of the soil-plant-air continuum. This variable is determined by a number of parameters including root zone hydraulic conductivity $(\mathrm{K})$. In this report we

Received for publication 17 July 2000. Accepted for publication 15 May 2001 We are grateful to the Joseph Hill Foundation and Roses Incorporated for providing financial support for this research. We also acknowledge assistance of Shlomit Medina who conducted measurements for the moisture retention curves. The cost of publishing this paper was defrayed in part by the payment of page charges. Under postal regulations, this paper therefore must be hereby marked advertisement solely to indicate this fact. have addressed this factor, which is closely linked to various soil properties, particularly water content $(\phi)$.

Roses represent one of the most important cut-flower crops in many countries. This crop is typically grown in greenhouses where optimal conditions are sought, so as to maximize production and timing of harvest to satisfy markets. Traditionally, this woody perennial has been grown in ground beds, but in recent years many rose growers have switched from soil to various containerized substrates, which have superior physical characteristics as compared to soil. Unlike in soil, matric potential $\left(\psi_{\mathrm{m}}\right)$ measured in porous media is usually quite low. Still, in many cases, water flux across the medium/root interface cannot match atmospheric demand for water, even under near-ideal aerial conditions. This is due to a sharp decrease in $\mathrm{K}$ with decreasing $\phi$, typical of most substrates (da Silva et al., 1993). A relatively small decrease in $\phi$ (e.g., of $1 \%$ to $5 \%$ ) may decrease $\mathrm{K}$ by an order of magnitude and thus greatly affect water availability to the roots (Wallach et al., 1992). This rate of decrease is much sharper than normally found in natural soils. Low $\mathrm{K}$ values indicate that the rhizoplane is exposed to tensions that are much higher than what can be measured in the bulk soil. da Silva et al. (1993) demonstrated that in substrates, the main limiting factor to water uptake is $\mathrm{K}$ and not $\psi_{\mathrm{m}}$, as measured in the bulk solution. To make an informed choice of a growing medium, the relationship between $\phi$ and $\mathrm{K}$ should be known. Measuring $\mathrm{K}$ in situ in porous media is laborious and cannot be done under commercial conditions. However, Raviv et al. (1999) demonstrated that reliable 
Table 1. Stomatal conductance and specific transpiration rate (STR) of fully expanded mature leaves of 'Kardinal' rose grown in UC mix or coir media, as a function of tension. Average of at least 25 observations per tension range and medium.

\begin{tabular}{|c|c|c|c|c|}
\hline \multirow{2}{*}{$\begin{array}{l}\text { Moisture } \\
\text { tension } \\
\text { range } \\
(\mathrm{kPa})\end{array}$} & \multicolumn{2}{|c|}{$\begin{array}{c}\text { Stomatal } \\
\text { conductance } \\
\left(\mu \mathrm{mol} \cdot \mathrm{cm}^{-2} \cdot \mathrm{s}^{-1}\right)\end{array}$} & \multicolumn{2}{|c|}{$\begin{array}{c}\mathrm{STR} \\
\left(\mu \mathrm{mol} \cdot \mathrm{cm}^{-2} \cdot \mathrm{s}^{-1}\right)\end{array}$} \\
\hline & $\mathrm{UC}$ mix & Coir & $\mathrm{UC}$ mix & Coir \\
\hline $0.8-1.5$ & $0.9 b^{z}$ & $1.4 \mathrm{a}$ & $7.4 \mathrm{~b}$ & 8.6 c \\
\hline $1.6-2.5$ & $1.0 \mathrm{~b}$ & $1.3 \mathrm{a}$ & $9.3 \mathrm{~b}$ & $12.9 \mathrm{a}$ \\
\hline $2.6-3.5$ & $0.8 \mathrm{a}$ & $0.9 \mathrm{a}$ & $8.5 \mathrm{a}$ & $10.1 \mathrm{a}$ \\
\hline $3.6-5.5$ & $0.8 \mathrm{a}$ & $1.0 \mathrm{a}$ & $7.1 \mathrm{a}$ & $7.8 \mathrm{c}$ \\
\hline
\end{tabular}

$\overline{{ }^{\mathrm{z}} \text { Mean separation within a row for stomatal conductance or STR by }}$ paired $t$ test at $P<0.05$.

models for K vs. $\phi$ and vs. $\psi_{\mathrm{m}}$ might be valuable for irrigation control.

Growth rate is often reduced from the maximum obtainable or potential growth rate by water and other environmental stresses. While it is a relatively simple matter to quantify growth, no reliable model for potential growth has been suggested in the past. Recently, microcalorimetry has been suggested as a method to characterize potential growth along with plant adaptation to various environmental conditions such as soil moisture tension and water availability (Criddle et al., 1991). It has been shown that specific growth rate estimations can be expressed as the difference between the rate of energy produced by respiration and the rate of energy lost to the surroundings as heat (Criddle et al., 1997). This calorimetric growth potential theory is based on the assumption that growth is maximal when the difference between respiration $\left(\mathrm{R}_{\mathrm{CO}_{2}}\right)$ and metabolic heat rates $(\mathrm{q})$ is largest in a given set of environmental conditions (e.g., specific temperature or soil moisture tension) (Hansen et al., 1994). The balance between $\mathrm{R}_{\mathrm{CO}_{2}}$ and q determines the rate of storage of chemical energy in structural biomass $\left(\mathrm{R}_{\mathrm{SG}}\right)$ and serves as an indicator for growth potential of the tested tissue (Hansen et al., 1997). The theoretical basis offered by Criddle et al $(1991,1997)$ and Hansen et al $(1994,1997)$ for predicting optimum conditions for growth has been supported in several experimental systems. Anekonda et al. (1994) found that in Coast redwood (Sequoia sempervirens $\mathrm{D}$. Don) $\mathrm{q}$ and $\mathrm{R}_{\mathrm{CO}_{2}}$ were highly correlated $(r=0.85)$ to various measures of growth (height, basal diameter and stem volume). Similar results were obtained when using microcalorimetry to predict the optimum growth conditions for tomato (Lycopersicon esculentum Mill.) and cabbage (Brassica oleraceae L.)(Criddle et al., 1991) as well as with larch [Larix laricina (Du Roi) K. Koch] (Hansen et al., 1989). Since water availability greatly affects growth rate, it was suggested by Hansen et al. (1997) that soil water status should also be reflected in calorimetric measurements.

The following research was conducted with two objectives. The first objective in the present study was to investigate the effect of physical characteristics of two media commonly used in greenhouse rose production on water availability to the roots, as reflected in yield, specific transpiration rate and stomatal conductance. The second objective was to test the hypothesis that soil water status affects potential growth rate, as predicted using calorimetry.

\section{Materials and methods}

Plant growth and measurement of transpiration rate. 'Kardinal' rose grafted on Rosa canina 'Natal Brier' were planted in ten 5-L containers per medium, filled with either coconut coir (composed of shredded, partly composted coconut husk fibers) or a UC mix [ $42 \%$ composted fir bark, $33 \%$ peat and $25 \%$ sand (by volume)]. The plants were grown in a glass-covered greenhouse at the Department of Environmental Horticulture, University of California, Davis, during October 1998 to August 1999. The depth of the medium was $18 \mathrm{~cm}$. Each plant had a space of 2700 $\mathrm{cm}^{2}$ (including aisle space). Since the plants were located within a rose stand, no border plants were assigned. The fertigation solution consisted of half-strength Hoagland solution (Hoagland and Arnon, 1950). Electrical conductivity of the solution was 1.0 $\mathrm{dS} \cdot \mathrm{m}^{-1}$. Minimal greenhouse temperature was 18 (C. Daytime temperature was kept below $28^{\circ} \mathrm{C}$ using evaporative cooling.

The plants were treated as a commercial rose crop. Weak stems were pinched and bent down to maximize photosynthesizing area. Flowers of commercial value were harvested at the normal opening stage. Stem length, fresh weight and leaf area were measured and flower quality was evaluated on a scale of 1 to $4,4=$ excellent in commercial terms, $3=$ fair, $2=$ acceptable, and 1 = unacceptable commercial quality.

Total leaf area of a rose plant is constantly changing. However, it is not practical and to some extent destructive to measure it on a daily basis. Instead, total leaf area was measured at the beginning and at the end of the experiment, and visually evaluated in between. The area of all removed leaves (mainly harvested flowers) was estimated using a quadratic relationship between measured leaf length and leaf area. Curves describing accumulated removed leaf area per each individual plant were developed and a leaf area growth rate was calculated from them. Correlation coefficients $\left(R^{2}\right)$ for these graphs were between 0.97 and $0.99(P$ $<0.01)$. These growth rates were used to construct a calculated
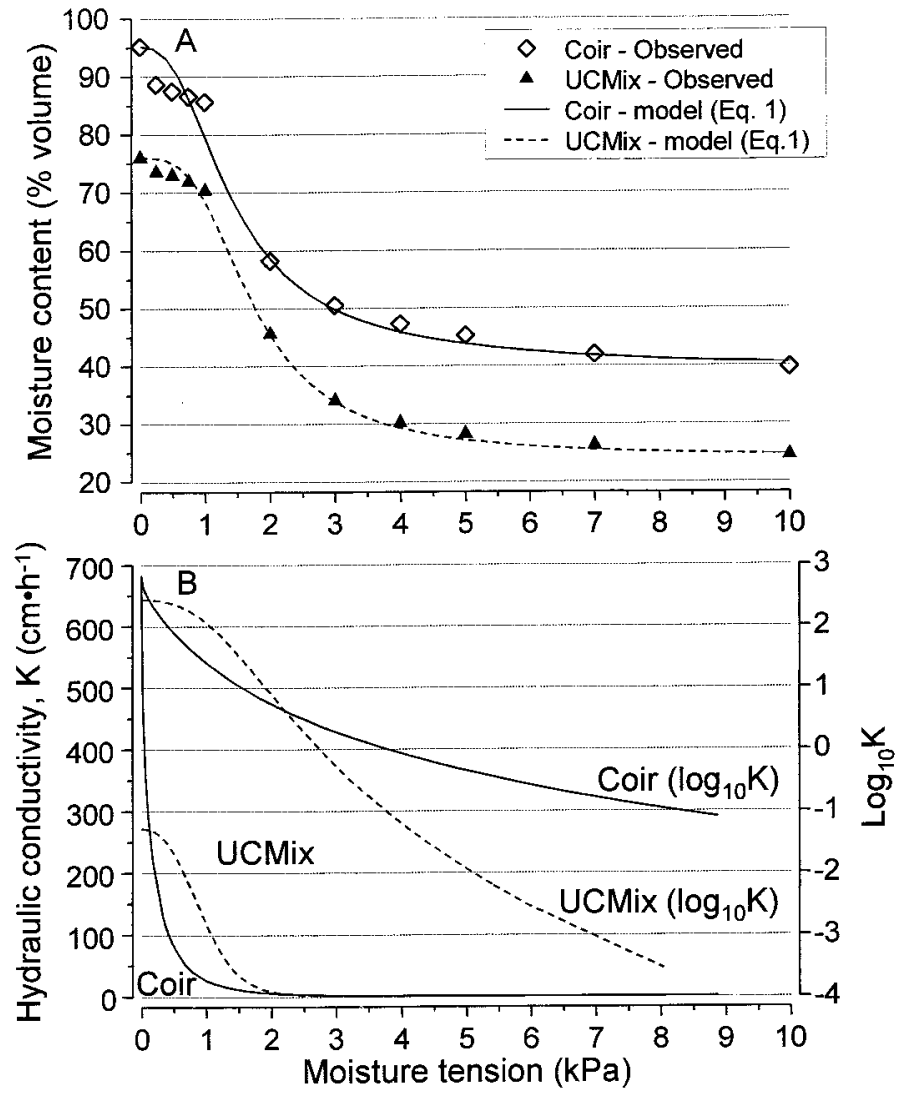

Fig. 1. (A) Water retention curves and observations for UC mix and coir and (B) calculated hydraulic conductivity $(\mathrm{K})$, as well as its logarithm of UC mix and coir with increasing substrate moisture tension. 
leaf area graph, for each individual plant. The initial and final measurements and the visual evaluations were used to validate the calculated leaf area and it was found that the curves provided an accurate measure of daily leaf area. Typical leaf area indices (total leaf area per unit surface area) fluctuated between 1.5 to 2.5 and typical daily relative growth rates were around 1.01 to 1.02.

Within each treatment, the weights of three plants were logged at 15-min intervals using load cells (model SP4-30KG; HBM Co., Marlborough, Mass.). $\psi_{\mathrm{m}}$ of four plants per medium was also recorded at 15-min intervals, using tensiometers equipped with high-flow ceramic tips and electronic pressure transducers (model LT; $15 \mathrm{~cm}$ long, Irrometer Corp. Riverside, Calif.). In addition to recording moisture tensions, the tensiometers (inserted to a depth of 10 to $11 \mathrm{~cm}, 7$ to $8 \mathrm{~cm}$ above the bottom of the container), were used to actuate an automated irrigation system based on tension setpoints. Usually, the setpoint for irrigation was $3 \mathrm{kPa}$. Twice a week, over the period April to July 1999, higher tension was applied to enable determination of specific transpiration rate (STR), stomatal conductance, and $\mathrm{R}_{\mathrm{SG}}$, over a wider range of moisture conditions. The irrigation pulses were of adequate volume to allow some water to drain out of the containers, so as to prevent salinity buildup, mimicking the commercial practice aimed at discharging excess nonnutritional ions. The media surface was covered with aluminum foil to minimize evaporation.

The relationship between STR and $\Psi_{\mathrm{m}}$ was determined using data collected between 1000 and 1300 HR on sunny days when no fertigation occurred and after any water drainage from the containers had ended. Any such data point constitutes a replicate, calculated against the average $\Psi_{\mathrm{m}}$ for this period. During this time frame greenhouse temperatures were maintained between 25 and $28^{\circ} \mathrm{C}$ using a fan and pad cooling system, resulting in relative humidity $(\mathrm{RH})$ values of $50 \%$ to $60 \%$. Typical photosynthetic photon flux [PPF (400 to $700 \mathrm{~nm}$ )] values above the plant canopy were 1000 to $1500 \mu \mathrm{mol} \cdot \mathrm{m}^{-2} \cdot \mathrm{s}^{-1}$. Direct measurements of stomatal conductance and STR were made on mature, fully expanded leaves during the same measurement time frame using a steady state porometer (LI-1600; LI-COR, Lincoln, Nebr.). At least 25 measurements were conducted per each moisture range per medium, against the actual $\psi_{\mathrm{m}}$, measured at the moment of the STR measurement (Table 1).

Physical Characteristics. Physical characteristics of the media (moisture retention and unsaturated hydraulic conductivity as a function of moisture content) were determined as follows. The moisture retention curves for the two media were measured using the method described by Raviv and Medina (1997) (Fig. 1). The model of van Genuchten (1980):

$\mathrm{S}_{\mathrm{e}=}\left[1+(\alpha \mathrm{h})^{\mathrm{n}}\right]^{-\mathrm{m}}$

was used to fit the measured retention curves. The variable $h$ in Eq. [1] is the moisture tension (centimeters of water) and $S_{e}=(\phi$ $\left.-\phi_{\mathrm{r}}\right) / \phi_{\mathrm{s}}-\phi_{\mathrm{r}}$ ) is the effective saturation, where the subscripts $\mathrm{s}$ and $r$ refer to the saturated and residual values of the moisture content, $\phi$, respectively. The parameters $\alpha, \mathrm{m}$, and $\mathrm{n}$ are empirical and determined by a best-fit procedure (van Genuchten et al., 1991). This model has been shown to describe the moisture retention curves quite well for various container media (da Silva et al., 1993; Wallach et al., 1992). The main advantage of Eq. [1] is the possibility of combining it with a predictive model for the hydraulic conductivity, $\mathrm{K}$, thus forming the basis for a combined hydraulic model. Substituting Eq. [1] into the model developed by Mualem (1976) for the relative hydraulic conductivity and assuming $\mathrm{m}=1-1 / \mathrm{n}$, leads to (van Genuchten, 1980)

$$
\mathrm{K}(\mathrm{h})=\mathrm{K}_{\mathrm{s}}\left\{1-(\alpha \mathrm{h})^{\mathrm{n}-1}\left[1+(\alpha \mathrm{h})^{\mathrm{n}}\right]^{-\mathrm{m}}\right\}^{2} /\left[1+(\alpha \mathrm{h})^{\mathrm{n}}\right]^{\mathrm{m} / 2}
$$

Wallach et al. (1992) and da Silva et al. (1993) applied this model for several container media resulting in $R^{2}>0.99, P<0.01$. The saturated hydraulic conductivity, $K_{s}$, of the two media was determined according to Hillel (1980) using glass columns having an inner diameter of $33.1 \mathrm{~mm}$ and filled with the media tested at a volume of $180 \mathrm{~cm}^{3}$. Ten replicates were conducted per medium.

Calorimetric measurements. Calorimetric measurements were made in complete darkness with a differential scanning calorimeter (model 4100; Calorimetry Sciences Corp., Provo, Utah) operated in isothermal mode $\left(25^{\circ} \mathrm{C}\right)$. Leaflets of uniform size and developmental age $(10 \mathrm{~mm}$ in length, 1 to $2 \mathrm{~d}$ after first visual appearance of the leaflet) were sampled from plants growing in the greenhouse at known $\Psi_{\mathrm{m}}$. Once removed from the plant, the leaflets were kept in a shaded and humid box until initiation of the calorimetric analysis that started no later than 5 min from leaflet detachment and lasted $<70 \mathrm{~min}$. The calorimeter had four removable ampoules, three of which were used for simultaneous measurements of rate of heat production with the remaining ampoule used as a control. Ampoules were thin-walled cylinders of $1 \mathrm{~cm}^{3}$ volume, constructed of Hastelloy $\mathrm{C}$ (a nickelchromium-molybdenum-tungsten alloy, supplied by Calorimetry Sciences Corp., with a screw cap sealed with a Viton gasket supplied by Calorimetry Sciences Corp. Fifty microliters of water was dispensed into the ampoules and the base of the leaflet was inserted into the water. This insured a $\mathrm{RH}$ inside the ampoule of $100 \%$ during measurements of $\mathrm{q}$ and $\mathrm{R}_{\mathrm{CO} 2}$. The $\mathrm{R}_{\mathrm{CO}_{2}}$ was determined via the methods of Criddle et al. (1991) and Fontana et al. (1990). $\mathrm{R}_{\mathrm{CO}_{2}}$ measurements were facilitated using the bottom 3 $\mathrm{mm}$ of a thin-walled micro Eppendorf tube. Called a base trap, these small containers were filled with $40 \mu \mathrm{L}$ of $0.4 \mathrm{~N} \mathrm{NaOH}$ and inserted into the ampoules to absorb $\mathrm{CO}_{2}$ produced by respiring tissue samples. The heat of the exothermic reaction between $\mathrm{CO}_{2}$ and $\mathrm{NaOH}$ forming carbonate was used to estimate respiration rates. This heat rate divided by the change in enthalpy between reaction of $\mathrm{CO}_{2}$ with $\mathrm{NaOH}$ in the base trap $\left(108.5 \mathrm{~J} \cdot \mathrm{mol}^{-1}\right)$ was used to determine $\mathrm{R}_{\mathrm{CO}_{2}}$ (Hansen et al., 1994). $\mathrm{R}_{\mathrm{SG}}$ was calculated by subtracting $\mathrm{q}$ from $\mathrm{R}_{\mathrm{CO}_{2}}$. Data were subjected to regression analysis and means were separated by paired $t$ tests using General Linear Models Procedures of the Statistical Analysis System (SAS Inst. Inc., Cary, N.C.).

\section{Results}

The moisture retention curves (Eq. [1], with $\mathrm{m}=1-1 / \mathrm{n}$ ) were able to represent the data of the two media well (Fig. 1A). The best-fit parameter estimates for $\alpha, \mathrm{n}$, and $\phi_{\mathrm{r}}$ for the two media are given in Table 2. Total porosity of the two media was $95.1 \%$ for coir and $76.0 \%$ for UC mix. At a tension of $1 \mathrm{kPa}, 9.5 \%$ and $5.6 \%$ of the volume of the pores became air filled in coir and UC mix, respectively, suggesting better aeration conditions in the root zone near container capacity of coir-grown plants. At $10 \mathrm{kPa}$, the moisture retention curves were close to the asymptotic moisture content of $39.7 \%$ and $24.5 \%$ for Coir and UC mix, respectively. On the whole, coir had a higher total porosity and free air space than the UC mix. However, the available water capacities (as defined by Bunt, 1988) were identical: water contents between 1 and $10 \mathrm{kPa}$ for both media were $46 \%$.

Measured saturated hydraulic conductivity $\left(\mathrm{K}_{\mathrm{s}}\right)$ of coir $(683$ 
Table 2. Estimated hydraulic parameters for the two media and the coefficients of determination $\left(R^{2}\right)$ of the curves between $\mathrm{X}$ and $\mathrm{Y}$ variables.

\begin{tabular}{lcccccc}
\hline \hline & \multicolumn{5}{c}{ Hydraulic parameters } \\
\cline { 2 - 6 } Medium & $\phi_{\mathrm{s}}$ & $\phi_{\mathrm{r}}$ & $\mathrm{n}$ & $\alpha\left[\mathrm{cm}^{-1}\right]$ & $\mathrm{K}_{\mathrm{s}}\left[\mathrm{cm}^{-1}\right]$ & 683 \\
\hline Coir & 0.95 & 0.382 & 2.67 & 0.087 & $R^{2}$ \\
UC mix & 0.76 & 0.245 & 3.34 & 0.066 & 272 & 0.993 \\
\hline
\end{tabular}

${ }^{\bar{z}} \phi_{\mathrm{s}}=$ water content at saturation, $\phi_{\mathrm{r}}=$ residual water content at $\mathrm{h}=100 \mathrm{~cm}, \mathrm{n}$, and $\alpha=$ empirical parameters of the best-fit procedure, and $\mathrm{K}_{\mathrm{s}}=\mathrm{hydraulic}$ conductivity at saturation.

$\left.\mathrm{cm} \cdot \mathrm{h}^{-1}\right)$, was much higher than that of the UC mix $\left(272 \mathrm{~cm} \cdot \mathrm{h}^{-1}\right)$. The difference was statistically significant at $P<0.001$. Calculated unsaturated hydraulic conductivity $(\mathrm{K})$ of coir declined very rapidly with increasing tension between 0 and $0.5 \mathrm{kPa}$, reaching equality with that of UC mix at $0.32 \mathrm{kPa}$ (Fig. 1B). Hydraulic conductivity of both media followed an asymptotic pattern, after an initial decline with increasing moisture tension. The different shapes of the two curves resulted in a higher K for UC mix in the range from 0.32 to $2.3 \mathrm{kPa}$. Above this tension range, $\mathrm{K}$ was low for both media but increasingly higher for coir than for UC mix (see $\log _{10} \mathrm{~K}$ curve in Fig. 1B). The sharp decline in $\mathrm{K}$ values within a relatively small range of tension values emphasizes the large effect that the resistance of water flow from the medium bulk to the root-substrate interface may have on the availability of water to the plant.

STR of the plants growing in the two media, as calculated using weight change by the load cells (Fig. 2), was higher for the coir-grown plants than UC mix-grown plants over the entire range of observed moisture conditions. Since STR was affected by changing ambient climatic conditions, $t$ tests were used to compare the effect of moisture tension on STR for the two media. Over the range 1.1 to $1.5 \mathrm{kPa}$, average STR of coir was $73 \%$ higher $(P<0.001)$ than that of UC mix. Over the range 1.51 to $3.75 \mathrm{kPa}$, average STR of coir was $29 \%$ higher than that of UC mix $(P<0.001)$. Over the range 3.76 to $9.9 \mathrm{kPa}$, average STR of coir was $13 \%$ higher than that of UC mix $(P<0.05)$.

Container weight patterns of UC mix- and coir-grown plants showed typical diurnal patterns (Fig. 3) of more rapid decreases in weight during day than during night, corresponding to the plants' water-use pattern. Once free drainage stops, the difference between the transpiration rates of the two media represents the

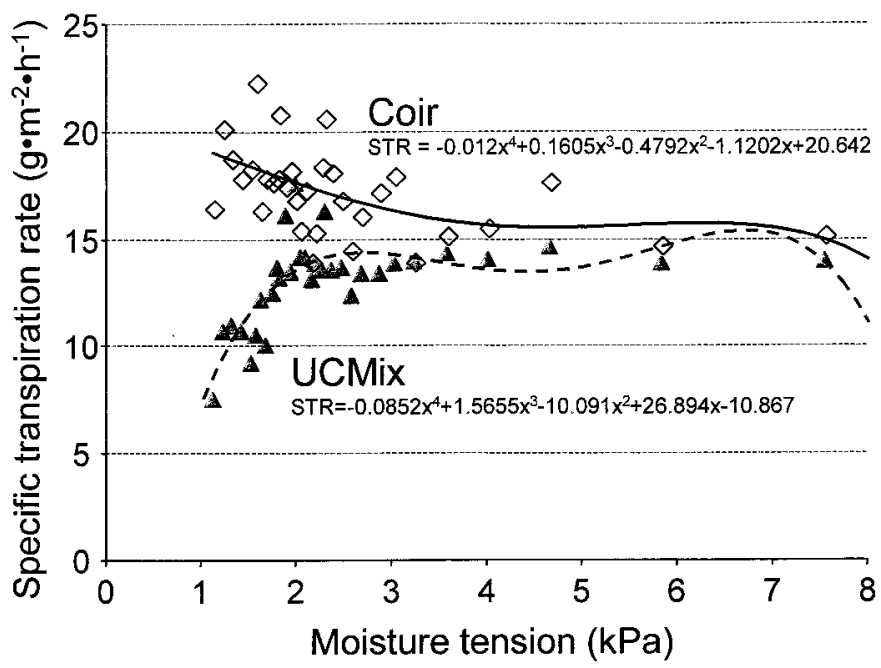

Fig. 2. Specific transpiration rate as a function of tension of 'Kardinal' rose plants, growing either in UC mix or in coir. See details of statistical difference between the fitted lines in text. difference in rate of weight change over time, which is consistently higher in coir $\left(35.1 \pm 2.6\right.$ and $20.8 \pm 2.4 \mathrm{~g} \cdot \mathrm{h}^{-1}$ for coir and UC mix, respectively). This resulted from both higher STR as well as higher leaf area of the coir-grown plants. Under our experimental conditions, the combined effect of these two factors was a higher moisture content (lower moisture tension) and lower free air space in the UC mix containers over long periods of time.

Direct measurement of individual leaf STR and of stomatal conductance using steady-state porometer led to similar conclusions (Table 1). The difference between whole canopy and individual STR values (Fig. 2 and Table 1) results from the measurement methodology. In the first case, the whole canopy of a single plant was considered. The individual, direct measurements were conducted using only leaves that were fully exposed to sunlight and were therefore more physiologically active than an average leaf. For porometry, the values were higher but relative difference between the media was lower than for gravimetric measurements. Stomatal conductance followed the same pattern as the STR and a significant difference between the two media can be found in the range 0.8 to $2.5 \mathrm{kPa}$ for both parameters.

The measured quality parameters of the flowers harvested from both media were not statistically different. However, coirgrown plants yielded 19\% more flowers than their UC mix counterparts (Table 3 ).

The effect of a range of $\psi_{\mathrm{m}}$ values on $\mathrm{R}_{\mathrm{SG}}$ shows differences between the two growing media (Fig. 4). Under the soil moisture tension conditions tested in both media $(0.7$ to $18.9 \mathrm{kPa}), \mathrm{R}_{\mathrm{SG}}$

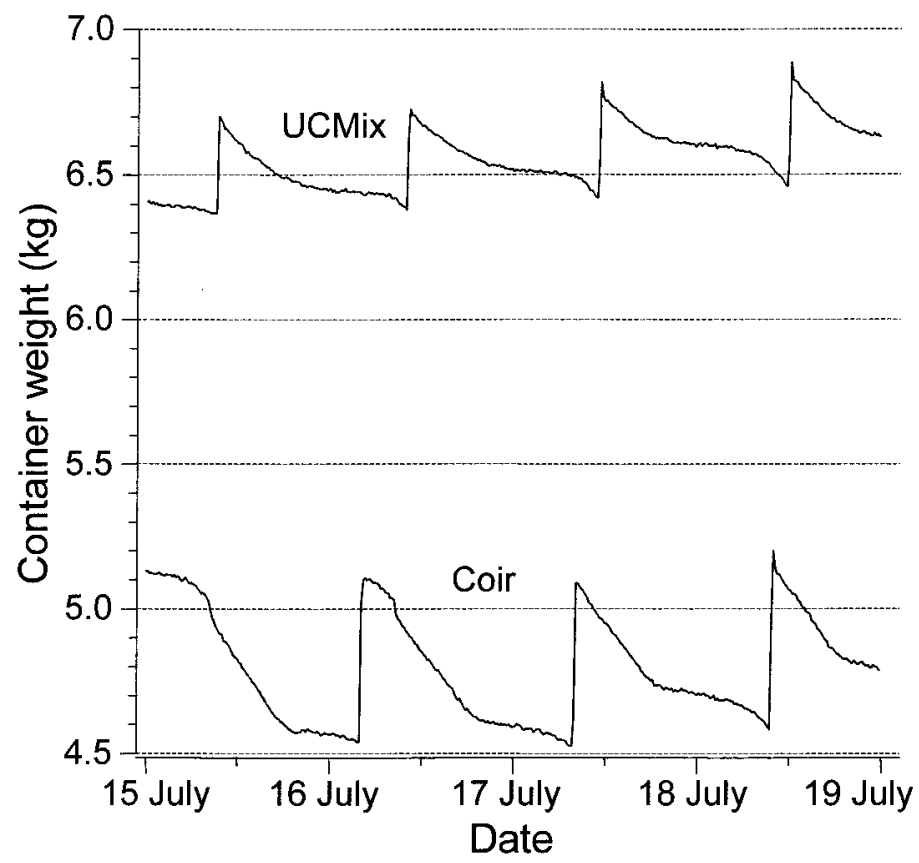

Fig. 3. Weights of containerized rose plants, grown either in UC mix or in coir over the period 15-19 July 1999. 
Table 3. Yield and quality parameters of UC mix- and coir-grown 'Kardinal' rose plants (average of 10 plants per treatment).

\begin{tabular}{|c|c|c|c|c|c|}
\hline Medium & $\begin{array}{c}\text { Flowers } \\
\text { per } \\
\text { plant }\end{array}$ & $\begin{array}{l}\text { Avg } \\
\text { flower } \\
\text { length } \\
(\mathrm{cm})\end{array}$ & $\begin{array}{c}\text { Avg } \\
\text { flower } \\
\text { wt } \\
(\mathrm{g})\end{array}$ & $\begin{array}{c}\text { Flower } \\
\text { quality } \\
(1-4)\end{array}$ & $\begin{array}{c}\text { Avg } \\
\text { leaf } \\
\text { flower } \\
\text { area } \\
\left(\mathrm{cm}^{2}\right)\end{array}$ \\
\hline$\overline{\mathrm{UC} \text { mix }}$ & $27.3 b^{z}$ & $53.6 \mathrm{a}$ & $40.2 \mathrm{a}$ & $3.2 \mathrm{a}$ & $456 \mathrm{a}$ \\
\hline Coir & $32.4 \mathrm{a}$ & $55.3 \mathrm{a}$ & $40.2 \mathrm{a}$ & $3.4 \mathrm{a}$ & $457 \mathrm{a}$ \\
\hline
\end{tabular}

${ }^{\mathrm{z}}$ Mean separation within columns by paired $t$ test at $P<0.05$.

values of leaflets from coir-grown plants were higher than those from UC mix-grown plants. Regression analysis showed the trends for both data sets to be curvilinear and significantly different from each other $(P<0.001)$. $\mathrm{R}_{\mathrm{SG}}$ values for rose leaflets from plants growing in UC mix decreased much more rapidly with increasing soil moisture tension than those from coir-grown plants. At a soil moisture tension level of $\approx 20 \mathrm{kPa}$, the growth potential of leaflets from UC mix-grown plants had decreased to zero, while the coir-grown plants continued to show positive leafgrowth potential. Ninety five percent confidence intervals show no overlapping between the two lines over the entire $\Psi_{\mathrm{m}}$ measured range. This probably suggests that $R_{\mathrm{SG}}$ is sensitive to both short periods of oxygen deficiency in the root zone and to water availability in the medium. As a result, plants grown in coir over this soil moisture tension range have a higher growth potential.

\section{Discussion}

Moisture retention curves for both coir and UC mix (Fig. 1A) were the result of the physical properties of their components. Since sand is not porous, and consists of a range of particle sizes which fit into the larger pores of the organic ingredients, UC mix had a lower total porosity than coir. At low tensions (up to $1 \mathrm{kPa}$ ), relatively more water was held by UC mix than by coir, resulting in an important difference in air content. When free drainage following an irrigation event stopped (known as container capacity), the container bottom was at saturation (zero moisture tension) while tension near the container surface was about $1.8 \mathrm{kPa}$

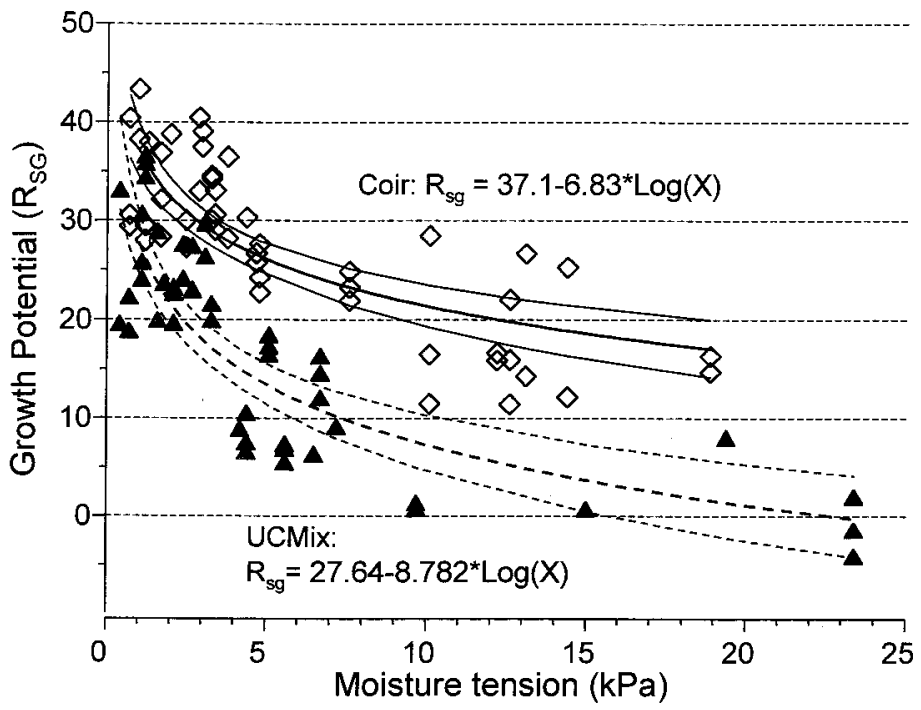

Fig. 4. Growth potential $\left(\mathrm{R}_{\mathrm{SG}}\right)$ of young 'Kardinal' rose leaflets estimated using calorimetric measurements taken from plants grown in UC mix or coir media at the measured moisture tension $(\mathrm{kPa})$. Thin lines on either side of the two regression lines are $95 \%$ confidence intervals. since the depth of the medium was $18 \mathrm{~cm}$. Since the tensiometer was located at a depth of 7 to $8 \mathrm{~cm}$, its reading at this stage was $\approx 0.7$ to $0.8 \mathrm{kPa}$. Corresponding volumetric air contents at the tensiometer tip were $3 \%$ for UC mix and $8 \%$ for coir. The former is considered to be an extremely low value (Bunt, 1988).

Hydraulic conductivity also varied with container depth. Hydraulic conductivity varied within this moisture tension range (and container depth) by about two orders of magnitude. This, coupled with the gravitropic growth habit of roots, were probably the causes for the common phenomenon of root mats near the bottom of the pot. In UC mix-grown plants, this dense root layer may be subjected to oxygen deficiency for a considerable length of time after an irrigation pulse. Suboptimal aeration decreases transpiration via its effect on root permeability and stomatal conductance (Drew and Stolzy, 1991; Kozlowski and Pallardy, 1984; Veen, 1988). The fact that roots concentrate at the bottom in spite of the periodic events of oxygen deficiency in this region, suggests that water stress is more damaging to their development than oxygen deficiency.

The momentary hydraulic conductivity of the medium solution, together with the difference between the $\Psi_{\mathrm{m}}$ at the medium-root interface and in the medium bulk, are measures for the ability of water to flow from the medium to the root-medium interface. This water flux should replenish water being withdrawn by the roots. Thus, it is inevitable that at some level of dryness, hydraulic conductivity will restrict water supply to the roots to the extent that it will be insufficient to meet transpirational demand of the plant. For example, assuming peak transpiration per plant of $500 \mathrm{~cm}^{3} \cdot \mathrm{h}^{-1}$ and a functional root surface area of $2000 \mathrm{~cm}^{2} /$ plant, we can estimate that a minimal $\mathrm{K}$ of $0.25 \mathrm{~cm} \cdot \mathrm{h}^{-1}$ (or $\log _{10} \mathrm{~K}(0.1)=-1$ ) would be required to constantly satisfy the demand for water which the plant is experiencing. This $\mathrm{K}$ value corresponds to a tension of up to $3.3 \mathrm{kPa}$ in UC mix and of $6.1 \mathrm{kPa}$ in coir. This suggests that coir affords plants the ability to avoid water stress better than UC mix by allowing for faster water movement at higher tensions.

The high $\mathrm{K}_{\mathrm{s}}$ of coir and its higher free air space at container capacity expose the roots of coir-grown plants to much shorter periods of oxygen deficiency than that of UC mix. Below $1.5 \mathrm{kPa}$, average STR values of plants grown in UC mix were much lower than those grown in coir (Fig. 2). STR of UC mix-grown plants also was lower than that of coir-grown plants in the range 1.5 to $2.3 \mathrm{kPa}$ where K of coir was lower than that of UC mix. This may result from the following sequence of events. A short period of oxygen deficiency may occur at the end of each irrigation cycle. The water retention curves (Fig. 1A) of the media suggest a longer period of oxygen deficiency for UC mix than for coir within the whole container volume. Furthermore, since the roots of both media are unevenly distributed within the container, with more roots located at the bottom than at the top, the root mat at the bottom may experience suboptimal aeration. This may happen while tension at the tensiometer tip, located at middepth and above the zone of saturation, is within the optimal range. This, again leads to higher oxygen deficiency in UC mix than in coir. The fact that roots formed mats at the bottom of the containers, where conditions of oxygen deficiency prevail, is apparently counter intuitive. This phenomenon may be a result of the gravitropic growth mode of roots and of the relatively greater negative impact caused to the 
roots by water shortage than by oxygen deficiency.

Differences in plants response to moisture content in the two media, despite identical available water capacities, underscore the fact that horticulturally, this term is less relevant than moisture tension, hydraulic conductivity, and oxygen content. The roles of free air space and hydraulic conductivity in determining the water status of the plant should be emphasized: free air space through its effect on oxygen availability to roots and hydraulic conductivity via its effect on water availability. A detailed study of physical and hydraulic characteristics of the media should be conducted whenever decisions are made regarding the suitability of media, so that the best choice of medium can be made and water availability can be optimized using control technology.

This study showed that use of microcalorimetry to estimate growth potential of young rose leaflets as affected by water availability is a useful tool. It appears that the high $\mathrm{R}_{\mathrm{SG}}$ values from plants grown under high tensions in coir as compared to UC mix are indicators of the positive effect of increased water availability on growth potential. This demonstrates how an environmental parameter such as water availability can directly affect metabolic heat and respiration rates of rose plants. This additional insight into the rose plant's basic metabolism, along with measurements of physiological response of stomatal conductance and STR, help to further explain how water availability can affect growth. Calorimetry can serve as a sensitive tool for explaining plant-environment interactions that will optimize growth-related horticultural processes.

\section{Literature Cited}

Anekonda, T.S., R.S. Criddle, W.J. Libby, R.W. Breidenbach, and L.S. Hansen. 1994. Respiration rates predict differences in growth of coast redwood. Plant, Cell and Environ. 17:197-203.

Bunt, A.C. 1988. Media and mixes for container grown plants. Unwin Hyman, London.

Criddle, R.S., R.W. Breidenbach, and L.D. Hansen. 1991. Plant calorimetry: How to quantitatively compare apples and oranges. Thermochimica Acta 193:67-90.

Criddle, R.S., B.N. Smith, and L.D. Hansen. 1997. A respiration-based description of plant growth rate responses to temperature. Planta 201:441-445. da Silva, F.F., R. Wallach, and Y. Chen. 1993. A dynamic approach to irrigation scheduling in container media, p. 183-198. In: Proc. 6th Intl. Conf. on Irrigation. Agritech, Ministry of Agriculture, Tel Aviv, Israel. Drew, M.C. and L.H. Stolzy 1991. Growth under oxygen stress, p. 331350. In: Y. Waisel, A. Eshel, and U. Kafkafi (eds.). Plant roots: The hidden half. Marcel Dekker, New York.

Fontana, A.J., L.D. Hansen, R.W. Breidenbach, and R.S. Criddle. 1990. Microcalorimetric measurements of aerobic cell metabolismin unstirred cell cultures. Thermochimica Acta 172:105-113.

Hansen, L.D., M.S. Hopkin, and R.S. Criddle. 1997. Plant calorimetry: A window to plant physiology and ecology. Thermochimica Acta 300:183-197.

Hansen, L.D., M.S. Hopkin, D.R. Rank, T.S. Anekonda, R.W. Breidenbach, and R.S. Criddle. 1994. The relation between plant growth and respiration: A thermodynamic model. Planta 194:77-85.

Hansen, L.D., E.A. Lewis, D.J. Eatough, D.P. Fowler, and R.S. Criddle. 1989. Prediction of long-term growth rates of larch clones by calorimetric measurement of metabolic heat rates. Can. J. For. Res. 19:606611.

Hillel, D. 1980. Fundamentals of soil physics. Academic Press, New York.

Hoagland, D.R. and D.I. Arnon. 1950. The water-culture method for growing plants without soil. Calif. Agr. Expt. Sta. Circ. 347.

Kozlowski, T.T. and S.G. Pallardy. 1984. Effect of flooding on water, carbohydrate and mineral relations, p. 165-193. In: T.T. Kozlowski (ed.). Flooding and plant growth. Academic Press, Orlando, Fla.

Mualem, Y. 1976. A new model for predicting the hydraulic conductivity of unsaturated porous media. Water Resources Res. 12:513-522.

Raviv, M. and Sh. Medina. 1997. Physical characteristics of separated cattle manure compost. Compost Sci. and Utilization 5:44-47.

Raviv, M., R. Wallach, A. Silber, Sh. Medina, and A. Krasnovsky. 1999. The effect of hydraulic characteristics of volcanic materials on yield of roses grown in soilless culture. J. Amer. Soc. Hort. Sci. 124:205-209.

van Genuchten, M.Th. 1980. A closed-form equation for predicting the hydraulic conductivity of unsaturated soils. Soil Sci. Soc. Amer. J. 44:892-898.

van Genuchten, M.Th., F.J. Leij, and S.R. Yates. 1991. The RETC code for quantifying the hydraulic functions of unsaturated soils. Environ. Protection Agency 600/2-91/065.

Veen, B.W. 1988. Influence of oxygen deficiency on growth and function of plant roots. Plant and Soil 111:259-266.

Wallach, R., F.F. da Silva, and Y. Chen. 1992. Hydraulic characteristics of tuff (scoria) used as a container medium. J. Amer. Soc. Hort. Sci. 117:415-421. 